\title{
The Status of Non-Communicable Disease Prevention and Control in the Philippines: A Systematic Review
}

\author{
Paul Adrian V. Pinlac,,$^{1}$ Eleanor C. Castillo, ${ }^{2}$ Jonathan P. Guevarra, ${ }^{2}$ Ivanhoe C. Escartin, ${ }^{3}$ \\ Ma. Elizabeth I. Caluag, ${ }^{4}$ Carmela N. Granada, ${ }^{4}$ Luz B. Tagunicar, ${ }^{5}$ Aurora D. Banda, ${ }^{3}$ John Juliard L. Go, ${ }^{6}$ \\ Jae Kyoun Kim, ${ }^{6}$ Christopher Allu S. Sy, ${ }^{7}$ Arvin A. Maceda ${ }^{7}$ and Nina G. Gloriani ${ }^{8}$ \\ ${ }^{1}$ Department of Epidemiology and Biostatistics, College of Public Health, University of the Philippines Manila \\ ${ }^{2}$ Department of Health Promotion and Education, College of Public Health, University of the Philippines Manila \\ ${ }^{3}$ Health Promotion and Communication Service, Department of Health \\ ${ }^{4}$ Lifestyle-Related Diseases Division, Disease Prevention and Control Bureau, Department of Health \\ ${ }^{5}$ Media and External Relations Division, Health Promotion and Communication Service, Department of Health \\ ${ }^{6}$ World Health Organization - Philippines \\ ${ }^{7}$ College of Public Health, University of the Philippines Manila \\ ${ }^{8}$ Department of Medical Microbiology, College of Public Health, University of the Philippines Manila
}

\begin{abstract}
Objective. This paper aims to provide concise background information regarding the state of noncommunicable diseases (NCDs) and their risk factors as well as the existing efforts to address them in the Philippines in the last 25 years.

Methods. A desk review of documents and literature review as well as analyses of available statistical data and several consultations with involved government agencies have been made to come up with summary figures and tables.
\end{abstract}

Results. NCDs as well as metabolic conditions that can potentially lead to NCDs are on the rise in the last score of years. The Philippines, through the Department of Health, has been visionary in leading various projects and activities to fight NCDs over the last two decades, and its efforts are slowly paying off: the prevalence of tobacco use and that of hypertension have decreased over the last 5 years. NCD mortality (including premature deaths) and prevalence of behavioral risk factors, however, generally remain high, and the Philippines needs to accelerate whole-of-society and whole-of-government actions to sustain the gains and attain its NCD targets in the next 10 years or so.

Conclusion. The need to strengthen health system interventions and promote accountability of various sectors in addressing NCDs and its risk factors in the country arises. The development of a multisectoral action plan on NCD prevention and control is needed to halt the rise of NCDs in the country.

Key Words: noncommunicable disease, risk factors, prevention and control

\footnotetext{
Corresponding author: Paul Adrian V. Pinlac, MD, MPH

Department of Epidemiology and Biostatistics

College of Public Health

University of the Philippines Manila

625 Pedro Gil Street, Ermita, Manila 1000 Philippines

Telephone: +6325247118 or 5260784

Email: pvpinlac@up.edu.ph
}

\section{Introduction}

Noncommunicable diseases (NCDs) have become the buzzword of health issues in the $20^{\text {th }}$ century. Ian R.H. Rockett (1999) was accurate when he described the shift from infectious diseases to chronic lifestyle-related diseases in the 1900s and predicted a final "hybristic" stage in his epidemiologic transition model which demonstrated the double burden shared by emerging infections and degenerative diseases. ${ }^{1}$ Indeed, our world today is a victim of both communicable diseases and NCDs, which are largely responsible distinctly for the global causes of morbidity and mortality, respectively.

The World Health Assembly, recognizing the need to address the turning epidemic that becomes of lifestylerelated diseases, has identified a threefold strategy to prevent and control NCDs: (1) prevention through actions on common modifiable risk factors for NCD such as tobacco use, harmful use of alcohol, unhealthy diet, and physical inactivity; (2) management of NCDs and metabolic conditions leading to these diseases utilizing cost-effective interventions; and (3) surveillance, or mapping and monitoring the emerging outbreak of NCDs and their determinants. $^{2}$ The last leg of this triad, surveillance, is crucial in that it provides the compelling evidence for appropriate action against NCDs and guides overall actions against NCDs. Goals would be set and targets prioritized following a careful identification of the key issues on the mounting yoke that is NCDs.

This paper aims to summarize the present state of NCDs in the Philippines and the current sociocultural and politicolegal milieu which promote or inhibit the development of these diseases and their risk factors. It is hoped that the background data presented in this article will be helpful in the subsequent planning of strategies and activities geared towards thwarting the growing problem of NCDs. 


\section{Materials and Methods}

Ongoing registry systems, recurring surveys, and sporadic studies from both the government and the private sectors which either regularly monitor trends or offer background information on NCDs and/or their behavioral and metabolic risk factors were identified by: (1) a series of three targeted roundtable discussions (RTDs) with several regional and local institutions, foremost of which are the World Health Organization-Western Pacific Region Office (WHO-WPRO), the Department of Health (DOH) and its attached agencies, and the Philippine Statistical Authority (PSA), tackling the increasing burden of NCDs in the country during the third quarter of 2014; and (2) an online search of publicly available documents in addition to existing publications on the economic burden of NCDs. The RTDs were part of a bigger project of the $\mathrm{WHO}$ and the $\mathrm{DOH}$ that intends to come up with a national strategic plan to combat NCDs; separate manuscripts as to the full approach as well as the results of these meetings are anticipated to be published following this paper. Meanwhile, extant literature has been collated from the WHO website (who.int), the MEDLINE repository of the U.S. National Library of Medicine via the PubMed portal, and the Google Scholar search engine, and reviewed to provide a more-orless cohesive scenario of NCD prevention and control in the country. Search terms included "noncommunicable disease," "cardiovascular disease," "heart disease," "stroke," "hypertension," "hypercholesterolemia," "diabetes," "obesity," "overweight," "physical activity," "tobacco," "smoking," "alcohol," “diet," "Philippines," "prevalence," and "economic burden," used singly or in combination with or without Boolean operators.

Methods of Analysis. Descriptive analyses of raw routinely collected administrative data were done. Consultations have likewise been carried out with different stakeholders in the form of key-informant interviews (KIIs) with the representatives from national and local government offices - the DOH Disease Prevention and Control BureauLifestyle-Related Disease Division (DOH-PCB-LRDD), the DOH Health Promotion and Communication Service (DOHHPCS), the DOH Health Policy Development and Planning Bureau (DOH-HPDPB), the National Nutrition Council (NNC), Philhealth, as well as selected local government units (LGUs), among many others - to be able to note and verify existing interventions and ventures against NCDs in the last 25 years. The result of these KIIs has been summarized as Tables 1 and 2 of this report.

Ethical Considerations. The statistical data used in this review study has been derived from secondary anonymous aggregate data routinely collected for administrative purposes primarily by the $\mathrm{WHO}$, the $\mathrm{DOH}$ and the PSA. Under this premise, there is no major issue regarding privacy and confidentiality that is expected to arise from the research. Meanwhile, verbal consent from the various stakeholders has been obtained during one of the RTDs prior to the conduct of KIIs in eliciting and corroborating qualitative information regarding NCD programs and activities.

Table 1. Summary of NCD Prevention and Control Efforts, Philippines, 1990-2014

\begin{tabular}{|c|c|c|c|c|}
\hline Time Span & NCD-specific & Healthy Lifestyle & Tobacco and Alcohol & $\begin{array}{c}\text { Diet and } \\
\text { Physical Activity }\end{array}$ \\
\hline $1990-1995$ & $\begin{array}{l}\text { Philippine Cancer Control Program } \\
\text { National CVD P\&C Program } \\
\text { Diabetes Mellitus P\&C Program }\end{array}$ & & Yosi Kadiri & $\begin{array}{l}\text { Tiya Kulit } \\
\text { Edi Exercise }\end{array}$ \\
\hline $1996-2000$ & $\begin{array}{l}\text { RA 8191: National Diabetes Act } \\
\text { Integrated NCD P\&C Program }\end{array}$ & & $\begin{array}{l}\text { Tobacco Control Program Framework \& } \\
\text { National Plan of Action } \\
\text { RA 8749: Clean Air Act }\end{array}$ & Iwas-Sakit Diet \\
\hline $2001-2004$ & $\begin{array}{l}\text { Integrated NCD P\&C Program } \\
\text { piloted in Pateros and Guimaras } \\
\text { Philippine Coalition for the P\&C } \\
\text { of NCD }\end{array}$ & $\begin{array}{l}\text { Mag-HL Tayo Campaign } \\
\text { Tulong-Sulong sa Kalusugan }\end{array}$ & $\begin{array}{l}\text { Global Youth Tobacco Survey } \\
\text { RA 9211: Tobacco Regulation Act } \\
\text { Smoking Cessation Program }\end{array}$ & $\begin{array}{l}\text { NNC incorporated } \\
\text { support for NCD-PC in } \\
\text { Philippine Plan of Action } \\
\text { for Nutrition }\end{array}$ \\
\hline $2005-2009$ & $\begin{array}{l}\text { Assessment of Guimaras and } \\
\text { Pateros } \\
\text { Updated Framework for Action } \\
\text { for NCD P\&C }\end{array}$ & $\begin{array}{l}\text { Presidential Proclamation 958: } \\
\text { Decade of Healthy Lifestyle } \\
\text { Healthy Lifestyle against } \\
\text { Cancer through Primary and } \\
\text { Secondary Prevention } \\
\text { Outstanding Healthy } \\
\text { Lifestyle Advocacy Awards }\end{array}$ & $\begin{array}{l}\text { Memorandum Circular No. } 17 \text { of CSC: } \\
\text { 100\% Smoke-Free Bureaucracy } \\
\text { Philippine Framework Convention on } \\
\text { Tobacco Control }\end{array}$ & $\begin{array}{l}\text { Advocacy on healthier } \\
\text { menu options initiated } \\
\text { DepEd Order No. } 8 \text { s. } \\
\text { 2007: Only nutrient rich } \\
\text { foods sold in school } \\
\text { canteens }\end{array}$ \\
\hline $2009-2014$ & $\begin{array}{l}\text { National Policy on Strengthening } \\
\text { the P\&C of Chronic LRNCD } \\
\text { Implementing Guidelines on } \\
\text { PhilPEN for PHC Facilities } \\
\text { TamaTseKaP Program }\end{array}$ & $\begin{array}{l}\text { Belly Gud Program } \\
\text { Pilipinas Go4Health }\end{array}$ & $\begin{array}{l}\text { Red Orchid Awards } \\
\text { DepEd Order No. 73: Smoke-free schools } \\
\text { MMDA: } 100 \% \text { Smoke-Free Policy } \\
\text { Revenue Memo. Order No. 16-2012: BIR } \\
\text { personnel to refrain from interaction } \\
\text { with Tobacco industries } \\
\text { RA 10351: Sin Tax Law } \\
\text { RA 10643: Graphic Health Warnings Law }\end{array}$ & $\begin{array}{l}\text { CSC: The Great Filipino } \\
\text { Workout } \\
\text { NNC: “Why Not?” TV } \\
\text { Program, Radyo Mo sa } \\
\text { Nutrisyon }\end{array}$ \\
\hline
\end{tabular}


Table 2. Some NCD Prevention and Control Efforts at the Level of the LGUs, Philippines

\begin{tabular}{|c|c|c|}
\hline LGU & Project & Details and Remarks \\
\hline Balanga City & $\begin{array}{l}\text { World-Class University } \\
\text { Town }\end{array}$ & $\begin{array}{l}\text { - Aggressive campaign against several health risk factors such as cigarette smoking, poor nutrition, } \\
\text { physical inactivity, substance abuse and excessive alcohol consumption } \\
\text { - Prohibition of establishments to offer services contrary to the ideals mentioned from three-kilometer } \\
\text { radius of the University Town Area } \\
\text { - Resulted to a significant decrease in the smokers prevalence rate and in the incidence of NCDs as well } \\
\text { as communicable diseases and other diseases }\end{array}$ \\
\hline Davao City & Smoke-Free Davao & $\begin{array}{l}\text { - Smoking ban on public places and designation of smoking areas in buildings to have special permits } \\
\text { - from City Engineer's office } \\
\text { - Requirement for establishments selling cigarettes required to apply for permits from city government } \\
\text { - Release of guidelines on tobacco sale } \\
\text { - Signing of Executive Order of No Tobacco Day every 31st day of May } \\
\text { - Government sponsorship of lectures and trimedia campaign on ill-effects of smoking } \\
\text { - Putting up smoking cessation clinics all over the city }\end{array}$ \\
\hline Marikina City & $\begin{array}{l}\text { Marikina Healthy City } \\
\text { Center }\end{array}$ & $\begin{array}{l}\text { - Provision of an environment supportive of healthy lifestyle-healthy parks, bicycle network, bicycle } \\
\text { and jogging lanes, Disiplina sa Bangketa, clean air and water campaign, carless day } \\
\text { - Implementation of Ordinance No } 200 \text { and } 201 \text { (creation of anti-smoking council, no smoking to } \\
\text { minors, no smoking in public places) } \\
\text { - Model Healthy City not only in the Philippines but throughout the Western Pacific Region }\end{array}$ \\
\hline $\begin{array}{l}\text { Municipality of } \\
\text { Bangued, Abra }\end{array}$ & $\begin{array}{l}\text { Healthy Lifestyle: The } \\
\text { Bangued Way }\end{array}$ & $\begin{array}{l}\text { - Adoption of a holistic approach towards NCD prevention by implementing various forms of physical } \\
\text { exercises in the Bangued LGU } \\
\text { - Improvement of sports facilities and venues for physical exercises and activities such as the municipal } \\
\text { plaza } \\
\text { - Anti-smoke belching campaign, Eco-Park construction and Clean and Green Program } \\
\text { - Enactment of EO No.14 in } 2001 \text { mandating the conduct of a 1-hour bi-weekly physical fitness program } \\
\text { called "Hataw Na: The Taebo Challenge" }\end{array}$ \\
\hline Municipality of & Integrated Community & - Development of risk assessment tool \\
\hline $\begin{array}{l}\text { Pateros, Metro } \\
\text { Manila }\end{array}$ & $\begin{array}{l}\text { Based NCD Prevention } \\
\text { and Control (DOH project } \\
\text { demonstration site) }\end{array}$ & $\begin{array}{l}\text { - Conduct of counselling sessions for diet, smoking and exercise } \\
\text { - Improvement of specialty clinics for diabetes and cardiovascular diseases } \\
\text { - Provision of rehabilitation services } \\
\text { - Creation of a Healthy Pateros Task Force that oversees different projects on NCD } \\
\text { - Declaration of the first week of December as the Healthy Pateros Week } \\
\text { - Creation of the Rainbow Tent-Health IsKOOL to promote healthy lifestyles in the community }\end{array}$ \\
\hline $\begin{array}{l}\text { Municipality of } \\
\text { San Jacinto, } \\
\text { Masbate }\end{array}$ & $\begin{array}{l}\text { Urosad sa Pahiwag (One in } \\
\text { Action) }\end{array}$ & $\begin{array}{l}\text { - Healthy lifestyle promotion and intensified information, education and communication (IEC) activities } \\
\text { for health workers regarding } 4 \text { pillars: physical activity, good nutrition, alcohol regulation, and } \\
\text { cessation of tobacco use } \\
\text { - Screening and referral for high-risk individuals } \\
\text { - Allotment of Php 50,000 annually for program implementation and Php 160,000 for medical supplies } \\
\text { - Resulted to a downward trend in the morbidity rate of hypertension and in the mortality rates of the } \\
\text { leading NCDs, particularly liver cirrhosis, cancer, CRDs, DM and CVDs }\end{array}$ \\
\hline Guimaras & Integrated Community & - Establishment of the Guimaras Unified Health Network \\
\hline Province & $\begin{array}{l}\text { Based NCD Prevention } \\
\text { and Control (DOH project } \\
\text { demonstration site) }\end{array}$ & $\begin{array}{l}\text { - Intensive information campaign } \\
\text { - Declaration of ports and public areas as smoke-free zones }\end{array}$ \\
\hline
\end{tabular}

\section{Results}

\section{The Socio-Cultural Milieu: The Escalating Burden of} NCDs

In the Philippines, the impact of NCDs is undeniable. A quick look at the leading etiologies of death in the country reveals that at least 6 out of the 10 listed are lifestyle-related or non-infectious in nature; ${ }^{3}$ also, it is estimated that twothirds of all deaths are due to NCDs. ${ }^{4}$ Furthermore, mortality arising from the four most common NCDs-cardiovascular disease (CVD), cancer, chronic respiratory disease (CRD) and diabetes mellitus (DM) - has been steadily rising in the last decade (Figure 1): there was a 50\% upsurge in deaths specific to NCDs between the years 2000 and 2010. All three aforementioned trends mirror those of the global scenario. 5,6,7

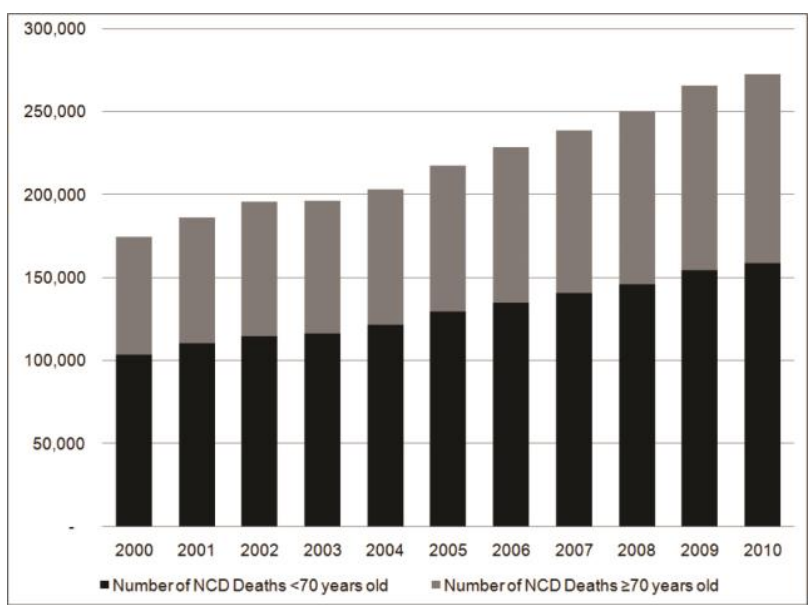

Figure 1. Number of NCD Deaths in the Philippines, 20002010 (Source: Author's calculation of NSO data) 
NCD deaths are disturbingly affecting the younger age groups, including the working age population, and this has implications to economic development. On the average, 59\% NCD deaths are premature or occurring earlier than age 70 . This is significantly higher than the international ballpark proportion of $48 \%$ in low- and middle-income countries, and an even farther cry from the approximated $26 \%$ in our more affluent counterparts. ${ }^{8}$ Worse, WHO pegs a Filipino's probability of dying from the leading NCDs at any age between 30 and 70 years old at $28 \%$ : this is higher than any of the estimates for its Southeast Asian neighbors ${ }^{3}$ (Figure 2).

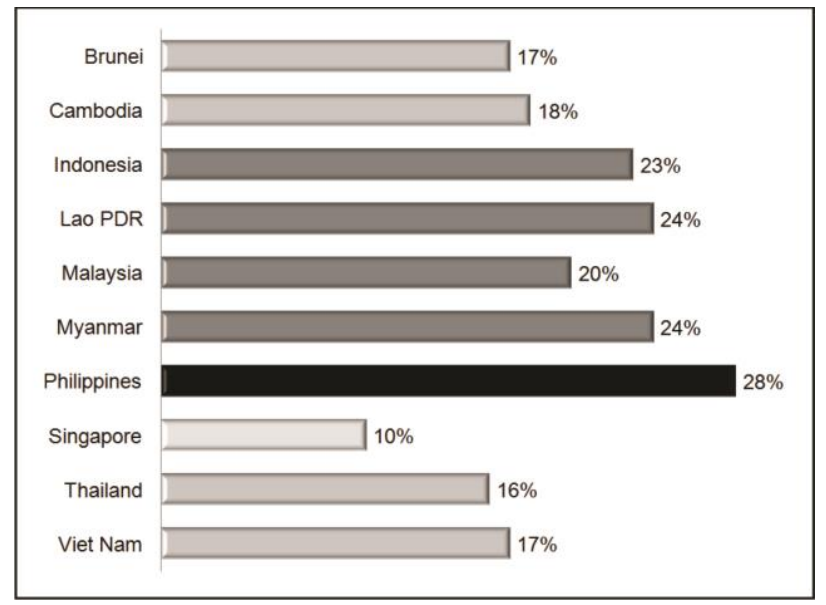

Figure 2. Probability of Dying Between Ages 30 and 70 Years from the 4 Main NCDs, ASEAN Member States, 2014 (Data source: WHO, 2014)

The increasing mortality from NCD and the percentage of premature NCD deaths are still reflected even when the different NCDs are taken individually (Figure 3). The count is highest and the rise is steepest for CVD, while cancers have the biggest proportion of NCD mortality younger than 70 years old at $73.7 \%$. Meanwhile, the number of NCD deaths is lowest for diabetes while the rate of increase is slowest in chronic lung diseases.

Aside from mortality, morbidity from NCDs is also on the rise. There are a little less than 100,000 estimated new cancer cases in the Philippines in 2012, and this figure is expected to almost double in the next two decades ${ }^{9}$ (Figure 4). Laudico and colleagues (2010) approximate that $44 \%$ of incident cancer cases are preventable; ${ }^{10}$ should this percentage hold true in the most current data available, this translates to precluding 43,230 new cancer cases at present and more than 83,000 new cases in 2035.
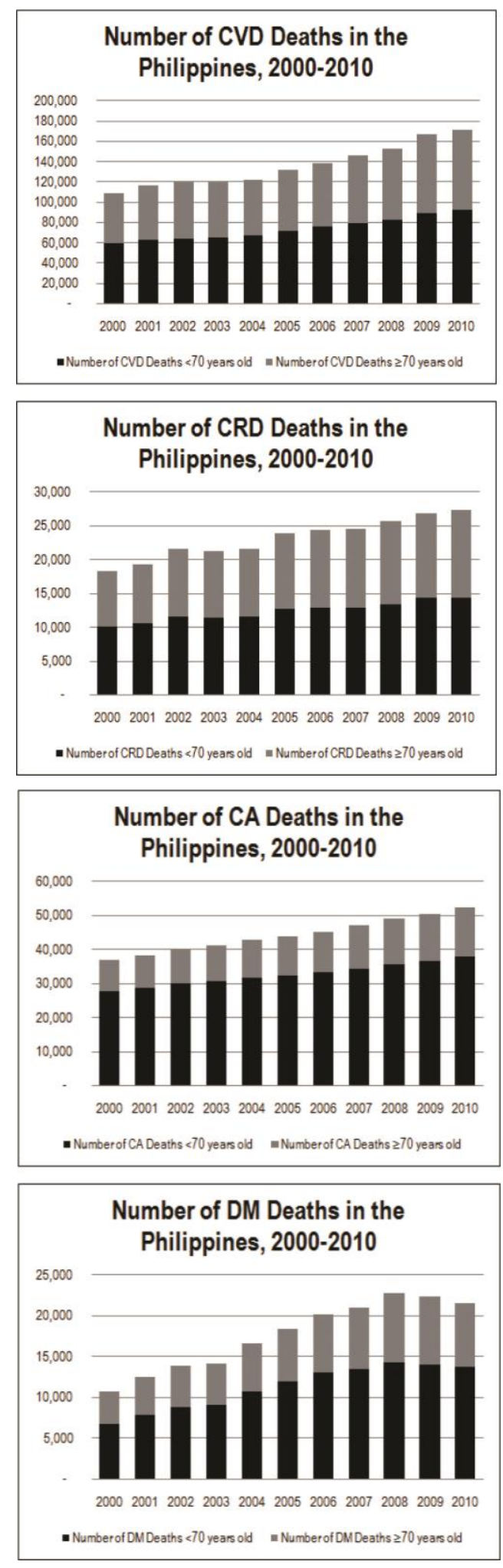

Figure 3. Number of Deaths from the Top 4 NCDs in the Philippines, 2000-2010 (Source: Author's calculation of NSO data) 


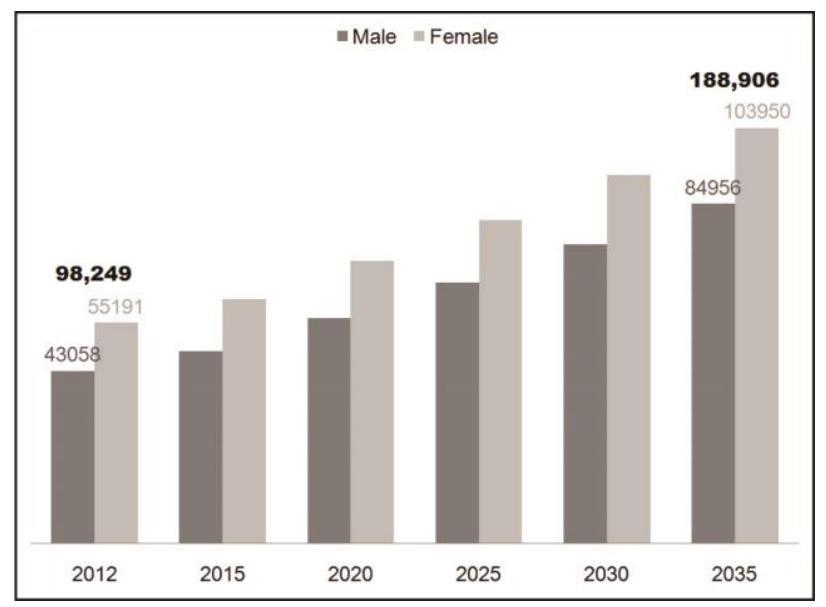

Figure 4. Estimated Number of New Cancer Cases, by Sex, All Ages, Philippines, 2012-2035 (Data source: GLOBOCAN 2012 [IARC, 2014])

Existing data on the prevalence of metabolic conditions potentially leading to NCDs (e.g., elevated blood pressure, elevated blood glucose, elevated serum cholesterol, overweight and obesity) likewise show an increasing trend in the last 20 years (Figure 5). Alarmingly, the prevalence of overweight and obesity among Filipino children and adolescents has a general tendency to increase, albeit gradually, over the years (Figure 6).

To date, one of every five Filipinos are hypertensive, one of every 20 are diabetic, and three of every 10 are overweight to obese (Figure 7). The prevalence of hypertension has been noted to decrease over the last 5 years (2008 to 2013), nonetheless it remains disturbingly high. Hypertension is the fourth leading cause of morbidity in 2010.11 Meanwhile, the proportion of diabetic and overweight and obese Filipinos continues to soar. Hypertension, as with the other CVDs, tends to have a predilection for males, while obesity is more common among females. Diabetes, on the other hand, manifests a marked difference between urban and rural settings, with a relatively higher prevalence in the former.

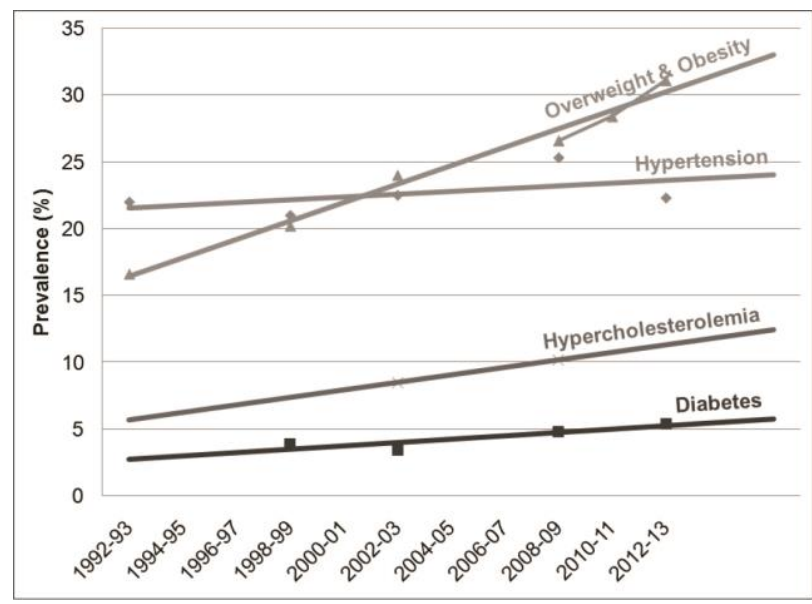

Figure 5. General Trends in the Prevalence of Metabolic NCD Risk Factors in the Philippines, 1992-2013 (Data source: National Nutrition Survey [FNRI-DOST])

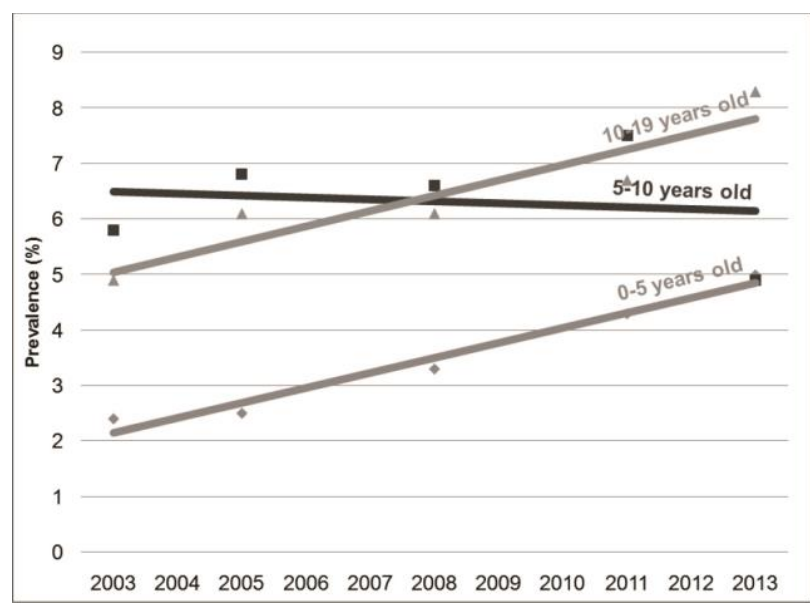

Figure 6. General Trends in the Prevalence of Overweightfor-height in Children and Overweight and Obesity in Adolescents, by Age Group, Philippines, 2003-2013 (Data source: National Nutrition Survey [FNRI-DOST])

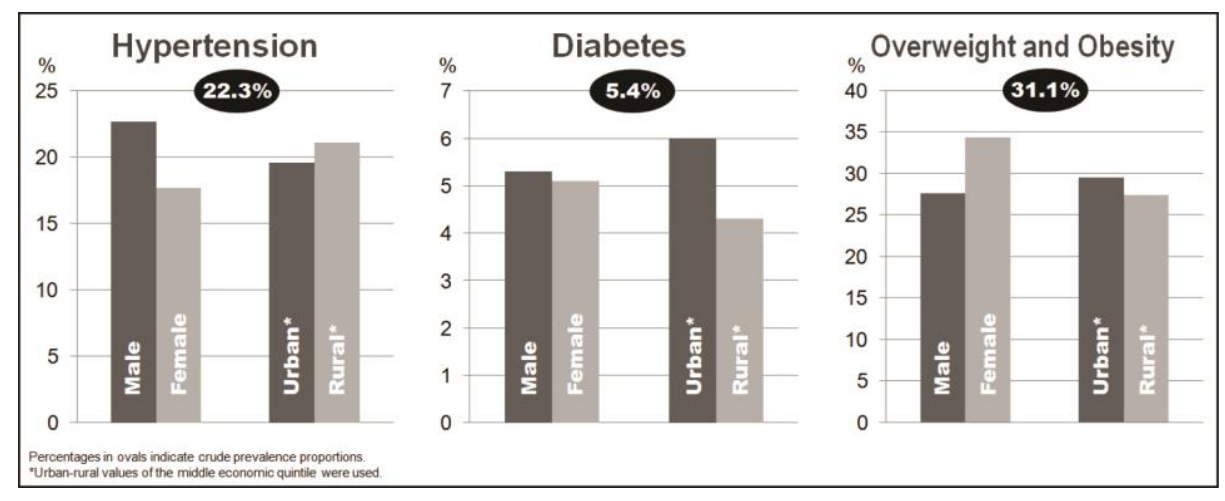

Figure 7. Prevalence of Metabolic NCD Risk Factors in the Philippines, by Sex and by Location, 2013 (Data source: National Nutrition Survey [FNRI-DOST]) 


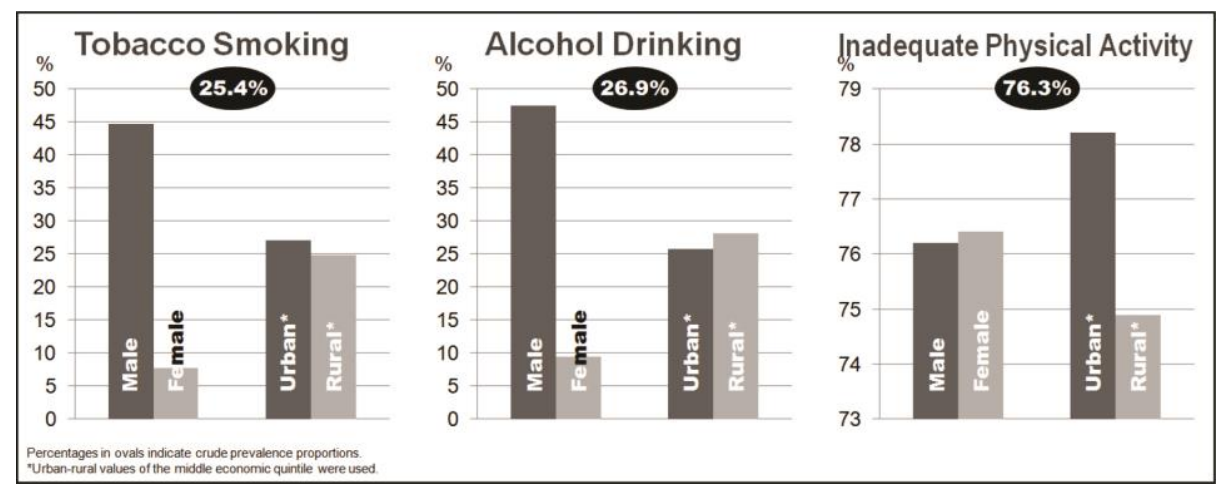

Figure 8. Prevalence of Behavioral NCD Risk Factors in the Philippines, by Sex and by Location, 2013 (Tobacco) and 2008 (Alcohol and Physical Inactivity) (Data sources: FNRI-DOST [for Tobacco and Alcohol] and PIDS [for Physical Inactivity])

As for the behavioral risk factors that promote the development of NCDs (Figure 8), in 2013, a quarter of Filipinos are current smokers, with $44.7 \%$ prevalence in males in contrast to $7.8 \%$ in females. ${ }^{12}$ Current alcohol drinking in 2008 is reported in one out of four Filipinos with a prevalence proportion of $47.5 \%$ in males, which is nine times higher than the prevalence in females. ${ }^{13}$ Meanwhile, physical activity is found to be sufficient only in $23.7 \%$ of Filipinos, ${ }^{14}$ and the proportion of inadequate physical activity is higher among those living in the urban areas than those in rural sites.

In general, adult smoking and drinking behaviors have been declining over the last 5-10 years (Figure 9), and this is largely attributed to sustained tobacco control measures being implemented nationwide. However, the change in the percentages for similar behaviors among adolescents has plateaued. During the past decade, $19.7 \%$ of $15-24$ year-olds were engaged in smoking while $36.7 \%$ are current drinkers. ${ }^{15}$ Despite the apparent decrease in the use of tobacco and alcohol, the prevalence of transitional states to NCDs - the metabolic or intermediate risk factors - are still on the rise, and this proclivity might continue to be observed in the next 20 years or so. Such is anticipated because of the lag time between the exposure to the risk factor and the development of the condition, otherwise known as the induction period. This is a predicament that the Philippines must be ready to face, since the natural consequence of chronic disease can be economically catastrophic. Smoking, which accounts for approximately $70 \%$ of lung cancer, $40 \%$ of chronic obstructive pulmonary disease (COPD), and 10\% of CVD, for instance, is projected to cost the Philippines 46 billion pesos annually wherein 27 billion pesos are spent on treatment of tobacco-related diseases, 1 billion pesos are lost in wages, and 18 billion pesos are productivity losses due to premature deaths. ${ }^{16}$ It is estimated that 181.5 billion pesos or $39 \%$ of the total health expenditure in 2012 was spent on NCDs. Expenditures were still predominantly out-ofpocket. ${ }^{17}$

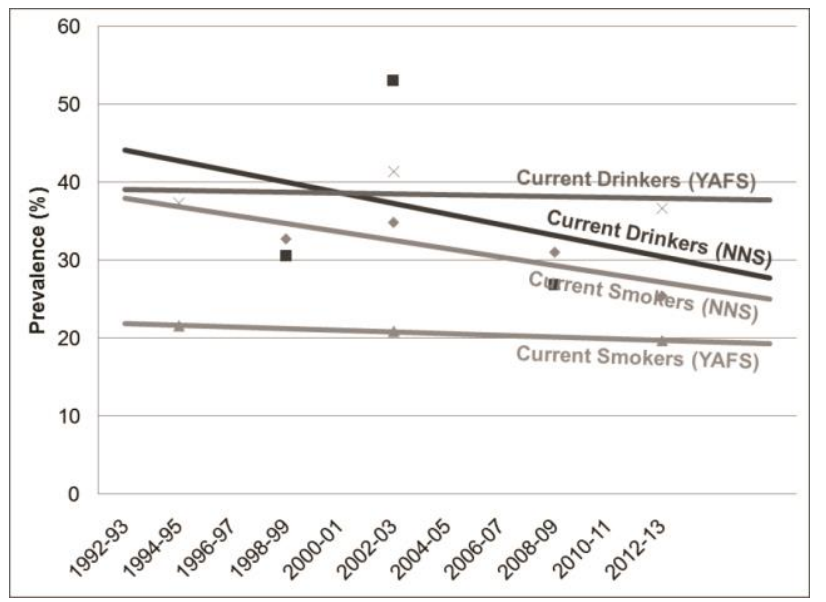

Figure 9. General Trends in the Prevalence of Behavioral NCD Risk Factors in the Philippines, 1992-2013 (Data sources: National Nutrition Survey [FNRI-DOST] and Young Adult Fertility Survey [UPPI-DRDF])

\section{The Politico-Legal Milieu: A Quarter of a Century's Work on NCDs}

The Philippines through its Department of Health has been proactive in combatting NCDs: as early as 1987, the Non-Communicable Disease Control Service (NCDCS) or the present-day Lifestyle-Related Disease Division of the health department was formed. ${ }^{18}$ Just 3 years later, the DOH launched its very first NCD-specific program-the Philippine Cancer Control Program (DOH-PCCP). The DOH-PCCP served as the kick-off for a series of other related prevention and control ( $\mathrm{P} \& \mathrm{C})$ programs, particularly on CVD and diabetes. Concomitant to the dawn of the P\&C programs were the humble beginnings of health promotion strategies on particular behavioral risk factors, namely, Yosi Kadiri (on smoking), Tiya Kulit (on diet), and Edi Exercise (on physical activity). 
The two decades that followed were marked by various programs, plans and activities that strengthened the good start that was. Among the more notable of these endeavors include the establishment of the Integrated NonCommunicable Disease Prevention and Control Program (INCDPCP); the conception of healthy lifestyle campaigns such as the Mag-HL Tayo, HL To The Max, and later the Pilipinas Go4Health; passage of the Tobacco Regulatory Act of 2003 and the adoption of the Framework Convention on Tobacco Control (FCTC) in the country, the provision of NCD medicines through the Complete Treatment Package (ComPack) Program and the adoption of the Philippine Package of Essential NCD Interventions (PhilPEN) at the primary healthcare level; and more recently, the passage of Republic Act Nos. 10351 (Sin Tax Law) and 10643 or (Graphic Health Warnings Law). These plus other major accomplishments of the health sector in the last quarter of a century are presented in Table 1.

Several other projects on NCD P\&C have been done in collaboration with or as an independent undertaking by other government offices. Agencies that are attached to $\mathrm{DOH}$ have lent the latter a hand in by incorporating of NCD P\&C in the Philippine Plan of Action for Nutrition, as in the case of the National Nutrition Council (NNC), or by supporting NCD management with the formulation of benefit packages, as in the case of the Philippine Health Insurance Corporation (Philhealth). Philhealth approved in 2012 the Primary Care Benefit Package 1 (PCB1) which provides outpatient NCDrelated preventive, screening, and diagnostic services at the level of the rural health units (RHUs). A PCB2 Package on outpatient medicines for hypertension, diabetes, and hyperlipidemia is currently piloted.

The Department of Education (DepEd) and the Department of Labor and Employment (DOLE) have become DOH's partners in implementing smoke-free environments and nutrition programs in schools and in workplaces, respectively. The Food and Nutrition Research Institute (FNRI) of the Department of Science and Technology (DOST) as well as the National Statistics Office (NSO) of the Philippine Statistics Authority (PSA) are DOH's allies in surveillance of NCD factors and outcomes. Other government units such as the Department of Interior and Local Government (DILG), the Commission on Higher Education (CHED), the Civil Service Commission (CSC), the Philippine National Police (PNP), and the Metro Manila Development Authority (MMDA), have ventured on similar individual $\mathrm{P} \& \mathrm{C}$ projects for targeted audiences. $\mathrm{DOH}$ has also worked with professional organizations and socio-civic groups to engage other stakeholders outside public offices; perhaps the most revolutionary of these efforts was the formation of the Philippine Coalition for the Prevention and Control of Non-Communicable Diseases (PCPCNCD), which convened more than 40 sectors back in 2006 and is still presently active. Topping the achievements of the
PCPCNCD are the enactment of Presidential Decree No. 958 which declared 2005-2015 as the Decade of Healthy Lifestyle and the development of the National Integrated Strategic Plan for NCD Prevention and Control 2005-2010.16

Local Actions against NCDs. As expected from a decentralized health system in the countries, local government units are in charge of implementing health programs within their jurisdictions. The DOH also encourages health promotion activities in key settingsschools, workplaces, and communities - as part of its efforts to curb NCDs. Examples of major environmental interventions at the LGU level are outlined in Table 2.

To see that these initiatives are not wasted and to encourage the burgeoning of these enterprises, $\mathrm{DOH}$ has come up with means to incentivize exemplary local government units (LGUs) and civil society alike. Together with the Philippine Coalition for the Prevention and Control of NCDs (PCPCNCD), the DOH has introduced the Outstanding Healthy Lifestyle Advocacy Awards (OHLAA), a biennial recognition activity that acknowledges the exceptional contribution of LGUs, nongovernment organizations (NGOs), professional organizations, schools, offices and commercial establishments to the promotion and adoption of healthy lifestyle in their respective areas. The promotion of the healthy lifestyle campaign is to be manifested by institutionalization of policies and innovative programs dealing with any of the common modifiable risk factors to NCDs: tobacco use, harmful alcohol use, unhealthy diet and physical inactivity.

The DOH also conducts annually the Red Orchid Awards for completely tobacco-free regional health offices, LGUs, and government offices and hospitals. Nominees to the award must be able to have instigated measures that will provide protection from environmental tobacco smoke (ETS) exposure, in accordance to the FCTC guidelines and Tobacco Regulation Act of 2003. Units which bag the trophy three times in a row are considered in the Hall of Fame. ${ }^{19}$ Since 2010, there have already been 370 Red Orchid awardees and 80 hall-of-famers; there are some 150 recipients of pink or white orchid awards or participation certificates. ${ }^{20}$ Some Red Orchid awardees have likewise been bestowed the OHLAA. ${ }^{21}$

\section{Discussion}

\section{The Philippines in the NCD 'Epidemic'}

How then does the country fare in the continuous fight against NCDs?

Strengths. The continuing commitment of the $\mathrm{DOH}$ and its long-standing history of NCD prevention and control work, together with the collaboration of strategic partners, including Philhealth, other government agencies, local government units, private sector, and civil society constitute a strong foundation and foothold in addressing the ever- 
growing burden of chronic diseases. The inclusion of NCDs as one of the priorities in the Kalusugang Pangkalahatan (Universal Healthcare) agenda of the $\mathrm{DOH}$ and the receptiveness of the Local Government Units to implement DOH-mandated cost-effective NCD interventions facilitates implementation of initiatives nationwide.

Weaknesses. With and despite the plethora of initiatives to address NCDs particularly at the national level, there seems to be a need for regular monitoring of some programs to ensure their sustained implementation on the ground. There is likewise a need for greater coordination across sectors by the $\mathrm{DOH}$ to avoid duplication and fragmentation of NCD-related efforts. In particular, $\mathrm{DOH}$ can provide more inspired leadership in multisectoral actions for NCD and overall coordination for surveillance activities, in line with the framework for NCD surveillance and the country's adoption of globally-mandated NCD targets.

Opportunities. The success of the laws on Sin Tax and the Graphic Health Warning, and other supportive policies for NCD prevention, the engagement of some health partners from other sectors, the demonstration of exemplary practices by LGUs, and the technical guidance provided by the World Health Organization provide a nurturing environment for continuing and improving efforts on NCD prevention and control in the country.

Threats. The big tobacco, big soda, and big food industries are potential threats to the NCD gains and efforts in the country. These industries and actual or perceived conflicts of interests between and among program partners, in addition to the potential effect of adopting the Western high-salt, high-sugar, high-fat, and low-fiber diet are substantial sources of friction in the push against NCDs.

In summary, there is yet:

- a need to EDIFY or strengthen the present approach to NCD prevention and control;

- a need to ENSURE accountability of NCD programs through more active surveillance;

- a need to ENSUE or follow through the Sin Tax Law, Graphic Health Warnings Law, PhilPEN, Philhealth NCD packages, and other cost-effective initiatives on NCD prevention and control; and

- a need to ENGAGE more socio-civic partners in the battle against NCDs through a multisectoral alliance.

\section{Acknowledgments}

The authors wish to thank Dr. Cherian Varghese, Senior Medical Officer, and Ms. Marie Clem Carlos, Technical Assistant of the World Health Organization (WHO) Regional Office for the Western Pacific, for providing the inspiration and direction in inditing this article.

The group also extends thanks to Mr. Yves Miel $\mathrm{H}$. Zuñiga, who has faithfully performed his duties as support staff to the University of the Philippines Manila-College of Public Health for this project.

The authors of this review paper are likewise grateful to the Vital Statistics Division of the Philippine Statistics Authority for its generosity in sharing some very important data that have been processed to come up with information specifically on mortality from NCDs.

\section{References}

1. Rockett IRH. Population and health: An introduction to epidemiology. Popul Bull. 1999; 54(4):1-44.

2. World Health Organization (WHO). Noncommunicable diseases: Realizing the commitments from heads of state and government made in the UN Political Declaration on NCDs [Online]. 2011 [cited 2012 Aug]. Available from http://globalhealthforum.net/wpcontent/blogs.dir/2/files/downloads/2012/08/Oleg-2012-UN-PoliticalDeclaration-on-NCDs.pdf

3. Department of Health (DOH). Leading causes of mortality [Online]. 2009 [cited 2011 Oct]. Available from http://www.doh.gov.ph/node/198.html.

4. WHO. Noncommunicable diseases (NCD) country profiles [Online]. 2014 [cited 2014 July]. Available from http://www.who.int/nmh/publications/ncdprofiles-2014/en/.

5. WHO. Global Health Observatory (GHO): NCD morbidity and mortality [Online]. 2014. Available from http://www.who.int/gho/ncd/mortality_morbidity/en/.

6. WHO. Package of Essential Noncommunicable Disease (PEN) interventions for primary health care in low-resource settings. Geneva: WHO Press; 2010, pp. 13-15.

7. WHO. WHO highlights need for countries to scale up action on noncommunicable diseases [Online]. 2014 [cited 2014 July]. Available from http://www.who.int/mediacentre/news/notes/2014/action-on-ncds/en/.

8. WHO. Global action plan for the prevention and control of noncommunicable diseases 2013-2020. Geneva: WHO Press; 2013, p. 7.

9. International Agency for Research on Cancer (IARC). GLOBOCAN 2012: Estimated cancer incidence, mortality and prevalence worldwide in 2012 [Online]. 2013 [cited 2013 December]. Available from http://globocan.iarc.fr/Default.aspx.

10. Laudico AV, Medina V, Mirasol-Lumague MR, Mapua CA, Redaniel MM, Valenzuela FG, Pukkala E. 2010 Philippine cancer facts and estimates. Manila: Philippine Cancer Society; 2010, pp. 6-8.

11. DOH. Field Health Services Information System (FHSIS). 2010.

12. Food and Nutrition Research Institute-Department of Science and Technology (FNRI-DOST). Initial Results of the 8th National Nutrition Survey (NNS). 2014.

13. FNRI-DOST. 7th NNS. 2008.

14. Ulep VT, Aldeon M, dela Cruz N. Discussion Paper Series No. 2013-40: Multisectoral strategy in addressing noncommunicable diseases in the Philippines. Makati: Philippine Institute for Development Studies (PIDS); 2013; p.14

15. University of the Philippines Population Institute-Demographic Research and Development Foundation (UPPI-DRDF). Young Adult Fertility and Sexuality Study (YAFS) 4. 2013.

16. Rivera JP, Reyes PO. Assessing the economic contribution of sin industries to the Philippine economy: The dilemma between macroeconomic growth and microeconomic welfare [Online]. 2012 [cited 2012 Feb]. Available from http://www.iioa.org/conferences/20th/papers/files/821_20120229010_IIOA2012 -Rivera\&Reyes-SinIndustriesinthePhilippines.pdf.

17. WHO. Philippine Health Accounts Estimates Study. 2012.

18. DOH. Twenty years of noncommunicable diseases prevention and control in the Philippines (1986-2006). Manila: Department of Health; 2009, pp. 15-67.

19. DOH. DOH Red Orchid Awards 2014: The search for $100 \%$ tobacco-free environments [Online]. 2013 [cited 2013 Dec]. Available from http://www.doh.gov.ph/sites/default/files/red_orchid_call_for_nomination_20 14.pdf.

20. DOH. Inventory of Red Orchid Awardees 2010-2014.

21. Banda AC. Outstanding Healthy Lifestyle Advocacy Awards 2013 winners: Building healthy communities workplaces and schools. HEALTHbeat. 2013; 79: pp. 28-33. 